\section{Буянов В.И.}

канд. психол. наук, доцент, ФГБОУ ВПО «Российский экономический университет им. Г.В. Плеханова», Москва e-mail: buvl@mail.ru

\section{Buyanov V.I.}

Ph.D. in Psychology, Associate Professor, FSBEI HE Plekhanov Russian University of Economics, Moscow

e-mail: buvl@mail.ru

\section{Анализ работ государственных гражданских служащих}

\author{
Аннотация \\ Статья посвящена анализу работ как первому этапу моделирования компетенций государствен- \\ ных служащих; работы соотнесены с решением управленческих, организационно-экономических \\ целей и задач. \\ Ключевые слова: \\ должность, анализ работ, анализ задачи, государственный служащий, компетенция, операция.

\section{The Job Analysis of Civil Servants} организационно-административных, организационно-методических и организационно-технических

\author{
Abstract \\ This paper has been devoted to the job analysis as the first stage of civil servants' competencies modeling \\ the jobs have been correlated with solution of managerial, organizational and economic, organizational and \\ administrative, organizational and methodical, organizational and technical goals and tasks.

\section{Keywords:} \\ position, job analysis, task analysis, civil servant, competence, procedure.
}

В отечественной теории и практике организации государственной гражданской службы одной из основных категорий, характеризующей субъекта этой службы и его профессиональную деятельность, является должность. Под должностью обычно понимают служебное место, а также профессиональную роль, выполняемую сотрудником государственного органа (организации).

Деятельность конкретного государственного гражданского служащего осуществляется в соответствии с должностным регламентом, содержание которого определено Федеральным законом от 27 июля 2004 г. № 79-Ф3 «О государственной гражданской службе Российской Федерации». Должностной регламент предусматривает: квалификационные требования к уровню и характеру знаний и навыков; должностные обязанности и ответственность за их неисполнение; права госслужащих; перечень вопросов, по которым гражданский служащий вправе или обязан самостоятельно принимать решения, а также участвовать при подготовке проектов решений; сроки и процедуры их подготовки и рассмотрения, порядок согласования и принятия данных решений; порядок служебного взаимодействия; перечень оказываемых государственных услуг, а также показатели эффективности и результативности профессиональной служебной деятельности гражданского служащего [1]. В то же время ни одним из руководящих документов не определена и не описана модель компетенций государственных гражданских служащих, в основе создания (моделирования) которой лежит анализ выполняемых им работ.

Для анализа работ государственного гражданского служащего могут приглашаться работники кадровой службы, линейный руководитель и ведущие сотрудники государственного органа, занимающие должность, для которой и разрабатывается перечень компетенций. Возможно (а иногда и необходимо) приглашение независимых экспертов. Смысл заключается в том, чтобы выделить основные действия (операции), которые выполняет служащий на той или иной должности, а также продукты этих действий.

Существует большое количество методов анализа работ, следовательно, и выделения операций, им соответствующих, каждый из которых дополняет другие $[2 ; 3$, с. 38-54].

Прогностическое интервью ориентировано на руководителей высшей группы должностей. Прогностическое интервью позволяет получить сведения о таких будущих изменениях в деятельности организации, которые могут повлиять на деятельность персонала и на требования, предъявляемые к нему. 
Поведенческое интервью предполагает рассмотрение отдельных примеров поведения госслужащего, которые должны быть рабочими, конкретными, недавними (не более двух лет назад), завершенными и с личным участием интервьюируемого.

Для получения полного поведенческого примера используется принцип, представленный в виде мнемонической аббревиатуры CARE (англ. care внимание):

- контекст, описание ситуации (Content) - Что это была за ситуация? Как и когда она произошла (закончилась)? Каковы основные обстоятельства ситуации? Кто еще участвовал в ситуации?

- действия (Action) - Каковы были основные этапы ситуации? Каковы были Ваши действия? С чего Вы начали и как развивались события дальше? Что Вы предприняли в этой ситуации?

- роль (Role $)$ - Как Вы можете описать свою роль в этой ситуации? Каков Ваш личный вклад? Как Вы оцениваете свои действия в ситуации? С какими сложностями Вы столкнулись? Что Вы предприняли, чтобы их преодолеть?

- результат $(E f f e c t)$ - Удалось ли Вам завершить начатое? Какие это имело последствия для Вас и организации (подразделения)? Чему Вы научились? Что бы Вы сегодня сделали иначе?

Метод критических инцидентов, разработанный Дж. Фланаганом в 1954 г., предполагает сбор описаний ситуаций, существенно повлиявших на достижение целей работы. При этом интервьюер просит сотрудника описать примеры своих как эффективных, так и неэффективных действий.

В основе метода репертуарных решеток лежит теория личностных конструктов (понятий), с помощью которых руководитель отличает успешных сотрудников от неуспешных. Проведя парные сравнения этих сотрудников, мы на выходе получаем конструкты, описывающие знания, навыки и свойства, необходимые для успешной работы.

Структурированные опросники построены так, чтобы после компьютерной обработки данных, полученных с их помощью, сформулировать как перечень работ, так и перечень соответствующих им компетенций сотрудников.

Большое количество необходимой для моделирования компетенций информации содержится в таких документах организации, как должностные регламенты, приказы и распоряжения руководства, входящая и исходящая корреспонденция и т.д. Анализ операций, которые есть в арсенале сотрудника, возможен на основе наблюдения и «фотографии» рабочего дня. Надежность такого наблюдения повышается, если его проводить в течение длитель- ного периода времени так, чтобы сотрудник не обращал внимания на присутствие эксперта.

Метод прямых атрибутов основан на анализе общих моделей с уже готовым перечнем работ. Подобные модели могут описывать большинство операций, которые делают сотрудники. Поэтому руководителей организации (экспертов) просят ознакомиться с содержанием этих операций и проранжировать их в порядке важности для исследуемой должности. Следует отметить, что данный метод применяется и при создании моделей компетенций, когда из общего списка компетенций отбираются наиболее важные для той или иной позиции [4].

В рамках НИР «Разработка модели типовых компетенций должностей государственных гражданских служащих», выполняемой лабораторией при кафедре Государственной службы и кадровой политики РАНХ и ГС в рамках Тематического плана Государственного задания на выполнение научно-исследовательских работ РАНХ и ГС 2014 г., была проведена операционализация работ, выполняемых государственными служащими. Нами был определен перечень основных операций, выполняемых государственными служащими, а также их результаты (продукты) (см. табл. 1). Данный перечень, составленный по алфавиту, довольно полно операционализирует деятельность государственных служащих, занимающих и исполняющих должности всех групп и категорий.

В дальнейшем с целью кластеризации работ они были соотнесены с решением управленческих, организационно-экономических, организационно-административных, организационно-методических и организационно-технических целей и задач. Так, в число «управленческих» операций вошли такие, как выдача указаний и распоряжений, делегирование полномочий, контроль принятого решения, разработка стратегии и плана, разрешение конфликтов и т.д. Ведение расчетов, составление бюджетов и отчетов, контроль исполнения бюджета составили перечень «организационно-экономических» операций. Организационно-административная деятельность государственных гражданских служащих представлена такими операциями, как ведение переговоров, наложение поошрений и взысканий, согласование, утверждение и подпись документов, прием посетителей, выдача справок и т.д. Решение организационно-методических задач предполагает проведение консультаций подчиненных, а также внутренних и внешних клиентов, проведение учебных занятий, презентаций и инструктажей. Наиболее широкий перечень операций соответствует решению организационно-технических задач, стоящих перед государственными гражданскими служащими. К ним относятся работа на компьютере, в 
том числе и с базами данных, выступление на радио и телевидении, оформление документов, написание текстов, записок, докладов, прием и совершение звонков по телефону, проведение опросов и интервью, ведение протоколов заседаний, поиск и передача информации и т.д. Интеллект-карта, на которой наглядно представлены основные операции, выполняемые госслужащими, соотнесенные с областями деятельности, представлена на рис. 1 .
Таким образом, нами проведен анализ основных операций, совершаемых государственными гражданскими служащими, который позволяет выйти на моделирование компетенций, что позволит руководителям, их помощникам, специалистам и обеспечивающим специалистам исполнять свои служебные должности с наибольшей эффективностью.

Таблица 1

Перечень основных операций, выполняемых государственными гражданскими служащими

\begin{tabular}{|c|c|c|c|}
\hline Вид операции & Результат & Вид операции & Результат \\
\hline 1 & 2 & 1 & 2 \\
\hline 1. Администрирует сайт & Обновленная страница сайта & $\begin{array}{l}\text { 29. Общается с представителя- } \\
\text { ми СМИ }\end{array}$ & $\begin{array}{l}\text { Информация о деятельности } \\
\text { организации (госоргана) }\end{array}$ \\
\hline 2. Берет интервью & Интервью & 30. Описывает имущество & Описанное имущество \\
\hline 3. Ведет допрос & Новая информация & 31. Офрормляет документы & Оформленный документ \\
\hline 4. Ведет переговоры & Соглашение, договор & 32. Охраняет & $\begin{array}{l}\text { Сохранное имущество и } \\
\text { безопасная деятельность } \\
\text { персонала }\end{array}$ \\
\hline 5. Ведет прием посетителей & Решение проблемы посетителя & $\begin{array}{l}\text { 33. Передает инфрормацию } \\
\text { через средства связи }\end{array}$ & Переданная информация \\
\hline 6. Ведет протоколы заседаний & Протокол & $\begin{array}{l}\text { 34. Пишет текст (доклад, } \\
\text { записку) }\end{array}$ & $\begin{array}{l}\text { Написанный текст (доклад, } \\
\text { записка) }\end{array}$ \\
\hline 7. Ведет расследование & Проведенное расследование & 35. Поощряет & Поощрение \\
\hline 8. Ведет расчеты & Сделанный расчет & 36. Принимает звонки & Принятый звонок \\
\hline $\begin{array}{l}\text { 9. Вносит изменения в должност- } \\
\text { ной регламент }\end{array}$ & $\begin{array}{l}\text { Обновленный должностной } \\
\text { регламент }\end{array}$ & $\begin{array}{l}\text { 37. Проводит анализ докумен- } \\
\text { тов }\end{array}$ & Выводы о качестве документа \\
\hline $\begin{array}{l}10 \\
\text { Выдает справки } \\
\end{array}$ & Выданная справка & 38. Проводит диагноз ситуации & Поставленный диагноз \\
\hline 11. Выписывает предписания & Выданное предписание & 39. Проводит инструктажи & $\begin{array}{l}\text { Проинструктированный } \\
\text { сотрудник }\end{array}$ \\
\hline 12. Выступает на радио (ТВ) & Выступление & 40. Проводит опросы & Проведенный опрос \\
\hline 13. Выступает перед аудиторией & Выступление & 41. Проводит презентации & Презентация \\
\hline 14. Дает указания и распоряжения & $\begin{array}{l}\text { Выданное указание } \\
\text { и распоряжение }\end{array}$ & 42. Проводит совещания & Решение \\
\hline 15. Делегирует полномочия & Делегированное полномочие & 43. Проводит учебные занятия & $\begin{array}{l}\text { Знания, навыки и умения } \\
\text { обучаемых }\end{array}$ \\
\hline 16. Досматривает & Найденная информация & 44. Работает на компьютере & Созданный документ \\
\hline 17. Ездит в командировки. & Поездка & 45. Размножает документы & Размноженный документ \\
\hline 18. Заполняет ведомости & Заполненная ведомость & 46. Разрабатывает документы & Разработанный документ \\
\hline 19. Звонит по телефону & Звонок & 47. Разрабатывает план & Разработанный план \\
\hline $\begin{array}{l}\text { 20. Использует информационные } \\
\text { БД }\end{array}$ & Найденная информация & 48. Разрабатывает стратегию & Разработанная стратегия \\
\hline 21. Ищет инсрормацию & Найденная информация & 49. Разрешает конфрликты & Разрешенный конфрликт \\
\hline 22. Консультирует подчиненных & Новые знания подчиненного & 50. Регистрирует документы & Зарегистрированный документ \\
\hline 23. Консультирует подчиненных. & Новые знания клиента & 51. Рекомендует & Рекомендация \\
\hline $\begin{array}{l}\text { 24. Контролирует исполнение } \\
\text { бюджета }\end{array}$ & Выявленные нарушения & $\begin{array}{l}\text { 52. Согласует, утверждает и } \\
\text { подписывает документы. }\end{array}$ & $\begin{array}{l}\text { Согласованный, утвержденный } \\
\text { и подписанный документ }\end{array}$ \\
\hline $\begin{array}{l}\text { 25. Контролирует принятое } \\
\text { решение }\end{array}$ & Выявленные нарушения & 53. Составляет бюджет & Составленный бюджет \\
\hline 26. Накладывает взыскание & Взыскание & 54. Составляет отчет & Составленный отчет \\
\hline 27. Накладывает штрафы & Наложенный штраф & 55. Ставит цели & Поставленная цель \\
\hline $\begin{array}{l}\text { 28. Обходит рабочие места } \\
\text { сотрудников }\end{array}$ & $\begin{array}{l}\text { Информация о сотрудниках } \\
\text { и их работе }\end{array}$ & & \\
\hline
\end{tabular}




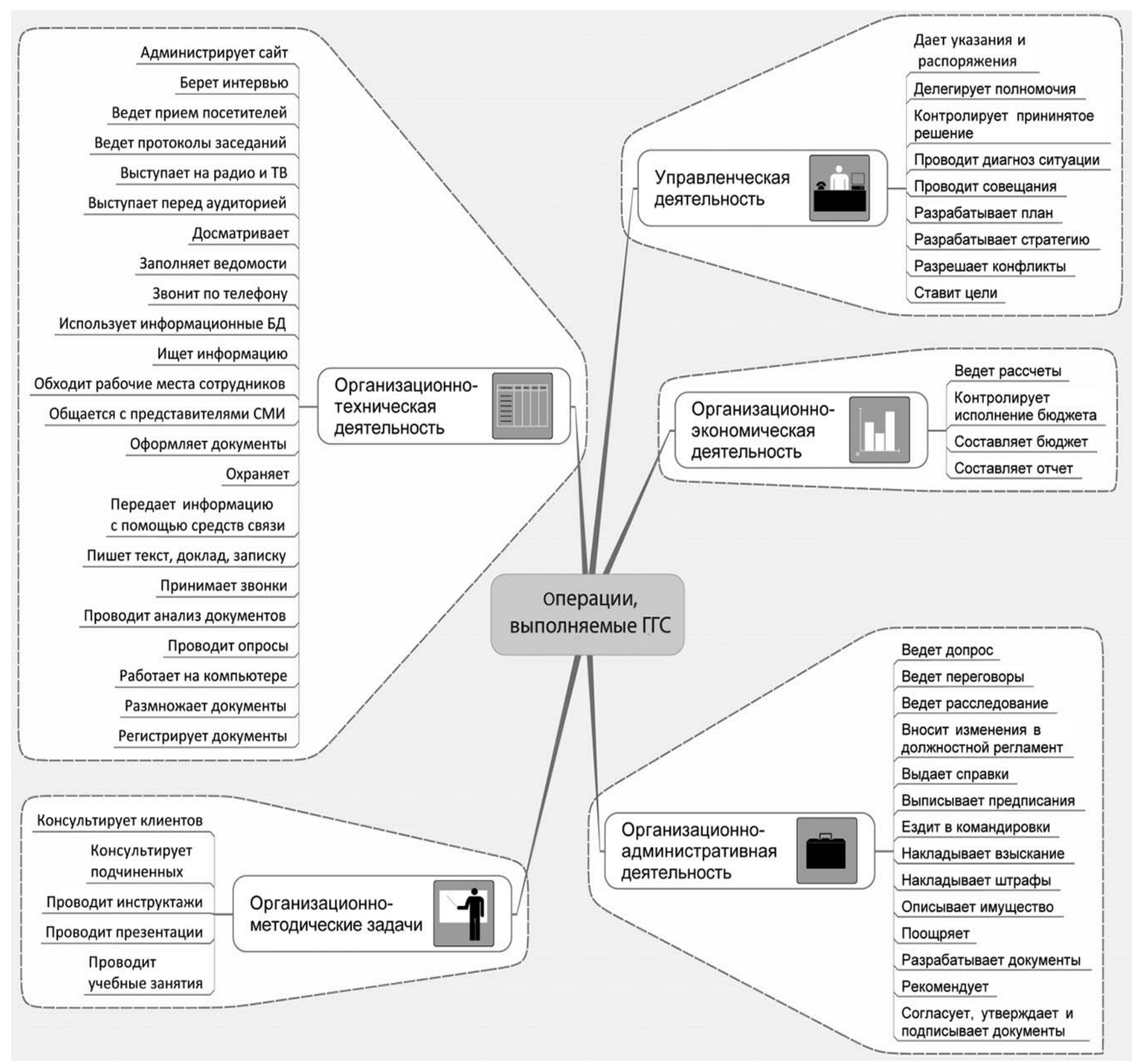

Рис. 1. Интеллект-карта основных операций, выполняемых государственными гражданскими служащими

\section{Литература}

1. Федеральный закон от 27 июля 2004 г. № 79-Ф3 «О государственной гражданской службе Российской Федерации» // Российская газета. - 2004. - № 3539.

2. Красностанова М.В. Assessment Center для руководителей: Опыт реализации, упражнения, кейсы [Текст] / М.В. Красностанова, Н.В. Осетрова, Н.В. Самара. М.: Вершина, 2007. - 208 с.

3. Спенсер Л. Компетенции на работе. Модели максимальной эффективности [Текст] / Л. Спенсер, С. Спенсер. М.: ГИППО, 2010. - $384 \mathrm{c.}$

4. Уиддет C. Руководство по компетенциям [Текст]/ С. Уиддет, С. Холлифорд. - М.: Нippo, 2003. - 228 с.

\section{References}

1. Federal Law of July 27, 2004 № 79-FZ “On the Russian Federation Civil Service" Rossijskaja gazeta [Russian newspaper]. 2004, I. 3539 (in Russian)

2. Krasnostanova M.V., Osetrova N.V., Samara N.V. Assessment Center dlja rukovoditelej: Opyt realizacii, uprazhnenija, kejsy [Assessment Center to leaders: implementation experience, exercises, case studies] Moscow, Vershina Publ., 2007. 208 p.

3. Spenser L., Spenser S. Kompetencii na rabote. Modeli maksimal'noj jeffektivnosti [Competence at work. Models maximum efficiency]. Moscow, GIPPO Publ., 2010. 384 p.

4. Uiddet S., Holliford S. Rukovodstvo po kompetencijam [Guide to Competency]. Moscow, Hippo Publ., 2003. 228p. 